\title{
EFFECT OF POST WELD HEAT TREATMENT ON METALLURGICAL AND MECHANICAL PROPERTIES OF ELECTRON BEAM WELDED AISI 409 FERRITIC STEEL
}

\author{
Akash Doomra ${ }^{1 *}$, Sandeep Singh Sandhu ${ }^{2}$,Beant Singh ${ }^{3}$ \\ ${ }^{I}$ Department of Mechanical Engineering, IK Gujral Punjab Technical University, \\ Kapurthala (Punjab), India \\ ${ }^{2}$ Department of Mechanical Engineering, Quest Infosys Foundation Group of \\ Institutions, Mohali (Punjab), India \\ ${ }^{3}$ Department of Mechanical Engineering, Universal Group of Institutions, Mohali \\ (Punjab), India
}

Received 12.08.2020

Accepted 10.09.2020

\begin{abstract}
The applicability of ferritic stainless steel is restricted due to its low weldability, and this can be attributed to the severe grain growth in the weld zone during the solidification of the weld pool and formation of fully ferritic structure. This study aims to investigate the weldability of $18 \mathrm{~mm}$ thick AISI 409 ferritic stainless steel plates using an electron beam welding process without the use of filler metal. The joints were investigated for metallography characterization (microstructure, macrostructure, and microhardness) and mechanical behavior (tensile strength and impact toughness) in aswelded condition and after post-weld heat treatment at $550{ }^{\circ} \mathrm{C}$ for 75 minutes. The weld zone exhibited large columnar grains in the direction perpendicular to the weld centerline and got refined after post-weld heat treatment. The ultimate tensile strength, yield strength, and microhardness of the weld zone were found higher than the base metal. The impact toughness of weld zone was found to be reduced by $45 \%$, but the post-weld heat treatment improved the toughness by $40 \%$. Results revealed that the electron beam welding process could be successfully employed for welding of AISI 409 ferritic stainless steel, which will increase its application range that requires thicker section of welded plates. Post-weld heat treatment was found to be advantageous for improving the microstructure and mechanical properties.
\end{abstract}

Keywords: AISI409 ferritic stainless steel; Electron beam welding; mechanical properties; microstructure analysis; post weld heat treatment; XRD; fractographs.

${ }^{*}$ Corresponding author: Research scholar, Akash Doomra, er.doomra@gmail.com 


\section{Introduction}

Ferritic stainless steel (FSS) is an iron-based alloy that contains $10.5-30 \%$ chromium contents and is identified by its fully ferrite structure after solidification [1, 2]. In the last decades, it has achieved a new position in the market by increasing its utilization share to $30 \%$ of the total steel production [3]. This gain in popularity is due to its high thermal conductivity, stress corrosion resistance, and low coefficient of expansion, which makes it suitable in numerous applications like exhaust manifolds, railway wagons, drums of machines, bus frames, electrical equipment, etc. [4-6]. They are considered as a low cost substitute to austenitic steel owing to its low nickel content $[7,8]$.

AISI 409 FSS has low chromium and carbon content, and it is utilized in applications exposed to gasses at high temperatures such as a silencer, boiler exhaust tubings, mufflers, etc. [9, 10]. Despite its great advantages and applications, still, its expansion is restricted due to poor weldability [11]. Severe grain growth in the regions exposed to heat, absence of any interphase precipitations, and formation of fully ferrite structure during solidification of the weld pool leads to a reduction in ductility and toughness of FSS [12]. Amuda and Mridha [13] reported that a slow cooling rate during welding gave sufficient time for grains to elongate, which further affects the metallurgical and mechanical properties. Mohandas et al. [14] compared the mechanical properties of a $3 \mathrm{~mm}$ thick FSS weld joint using gas tungsten arc welding(GTAW) process and shielded metal arc welding (SMAW) process. The authors concluded that the joints fabricated using low heat input (GMAW) process gave better strength and ductility in comparison to the high heat input (SMAW) process. Lakshminarayanan et al. [15] compared three types of arc welding processes by welding $4 \mathrm{~mm}$ thick AISI409M FSS and concluded that weld joints prepared from the pulsed arc welding process exhibit higher mechanical properties and finer grains structure due to less heat input during welding than the weld joints made from the continuous current arc welding process and plasma arc welding process.

The literature survey related to the weldability of FSS, suggests using low heat input welding techniques aided refined microstructure and enhanced mechanical properties[7]. Unconventional welding process viz. laser beam welding (LBW) and electron beam welding (EBW) processes and solid-state welding techniques such as friction stir welding (FSW), were found more advantageous owing to their low heat input than the conventional welding processes[16-24]. Although FSW of ferritic stainless steel is restricted due to difficulties experienced such as tool wear, lower weld speeds, and requirement of a very tight clamping of plates before welding, power beam welding techniques such as LBW and EBW are very promising in this respect. The EBW process works on a high-density beam that makes it feasible to achieve highquality weld at low heat. The EBW process offers many advantages such as deeper weld, small weld zone, and heat-affected zone, high cooling rate, minimum weld defect, etc. [25]. It can be used to weld different grades of steel with the thickness of the plate up to $280 \mathrm{~mm}$ [26]. Lakshminarayanan et al. [27] employed the EBW process to weld $4 \mathrm{~mm}$ AISI 409M ferritic steel and mentioned the formulation of fine grains in the weld zone (WZ) and also the toughness was also retained. Tullmin et al. [28] made a comparison of microstructural and mechanical properties of a $6 \mathrm{~mm}$ weld joint between the laser beam and electron beam process. The authors mentioned that higher impact toughness was achieved with the EBW process, and grain growth due to thermal cycles 
was minimum in both cases. Havlik et al. [29] investigated the microstructure behavior of ferritic steel, martensite steel, and austenite steel using an EBW process and mentioned that the solidification rate of the WZ controls the final formation of the microstructure. The grain size was smaller for higher cooling rates [30].

It has also been suggested by the various researcher that post-weld heat treatment (PWHT) of ferritic stainless steel reduces the residual stresses and improves the toughness and ductility of the weld joints [4, 10, 31-34]. Vidyarthi et al. [35] investigated the influence of PWHT on the metallurgical and mechanical properties of AISI 409 ferritic steel. The impact toughness was found to be critically reduced after welding, but the application of PWHT sufficiently improved the properties. Manugula et al. [36] also mentioned the improvement in impact toughness after the successful implementation of PWHT when welded using the EBW process.

The recent advancements in research and technology have made possible to weld AISI 409 FSS under certain welding conditions but still the non-occurrence of phases during solidification of weld zone has restricted to weld up to certain thickness ( $3 \mathrm{~mm}$ to $12 \mathrm{~mm}$ ) but some application like agricultural parts, railways wagons requires the use of the thicker welded plate. Several researchers had worked on welding of various grades of ferritic stainless steel by the EBW process, but the study on AISI 409 FSS is very scant. In this research work, an attempt has been made to weld $18 \mathrm{~mm}$ thick AISI 409 FSS plates using an electron beam welding process in a single pass. Wherein metallographic and mechanical properties were analyzed in terms of macrostructure analysis, microstructure analysis, microhardness measurements, XRD analysis, tensile strength, impact toughness, and fractography in as-welded and after post-weld heat treatment at $550{ }^{\circ} \mathrm{C}$ for 75 minutes.

\section{Experimentation Procedure}

\section{Material and methods}

AISI 409 standard cold rolled ferritic stainless steel plates with a thickness of $18 \mathrm{~mm}$ were used in this study. The chemical composition in wt $\%$ was analyzed through a spectroscopic test. Table 1 shows the obtained chemical composition of AISI 409 FSS substrate plate. The plates were prepared to the size $200 \times 75 \times 18 \mathrm{~mm}$, and the butt edges were precisely machined to $90^{\circ}$ to obtain a high-quality butt joint. Prior to welding, the plates were thoroughly cleaned mechanically with a brush and chemically with acetone to remove dust and unwanted particles.

Table 1. Chemical composition of AISI 409 FSS plates.

\begin{tabular}{llllllllllllllll}
\hline $\begin{array}{l}\text { Chemical } \\
\begin{array}{l}\text { Composition } \\
\text { (wt } \%)\end{array}\end{array}$ & C & Si & Cr & Mn & Ti & P & S & Ti & Mo & Nb & Al & V & Fe \\
\hline AISI 409 & 0.014 & 0.39 & 11.43 & 0.582 & 0.18 & 0.02 & 0.007 & 0.18 & 0.023 & 0.015 & 0.00 & 0.017 & $\mathrm{Bal}$ \\
\hline
\end{tabular}

The plates were rigidly clamped to the bed of EBW machine, and a backing plate of the same material was used at the bottom to restrict the flow of the weld pool. Trial runs were conducted prior to the final weld for the finalization of welding parameters that leads to through-thickness weld. The final butt weld was achieved in an autogenous mode without the filler metal. The welding parameters utilized to achieve the weld are 
shown in Table 2, and the welded plate is shown in Fig. 1. After completion of the weld, the joints were inspected for quality through ultrasonic testing and liquid penetrant testing, and the weld joints were found defect free.

Table 2. Optimized parameters used for obtaining the weld.

\begin{tabular}{ll}
\hline Parameters & Value \\
\hline Voltage & $150 \mathrm{kV}$ \\
\hline Current & $90 \mathrm{~mA}$ \\
\hline Speed & $700 \mathrm{~mm} / \mathrm{min}$ \\
\hline Heat Input & $1.28 \mathrm{~kJ} / \mathrm{mm}$ \\
\hline Vacuum & $5 \times 10^{6} \mathrm{bar}$ \\
\hline
\end{tabular}

*The heat is obtained by $\eta(\mathrm{VxI}) / \mathrm{S}$, whereas $\eta$ is the welding source efficiency and considered as 0.95

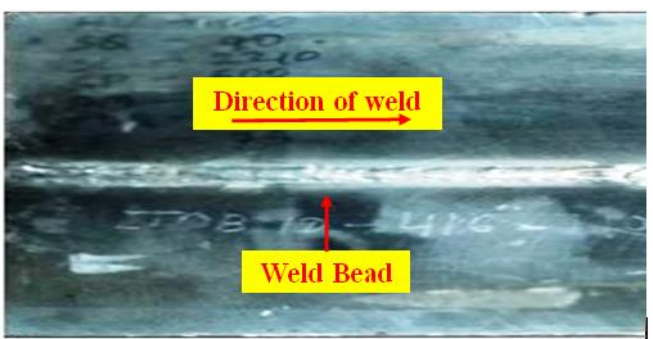

Fig. 1. Electron beam welded plate of AISI 409 ferritic stainless steel.

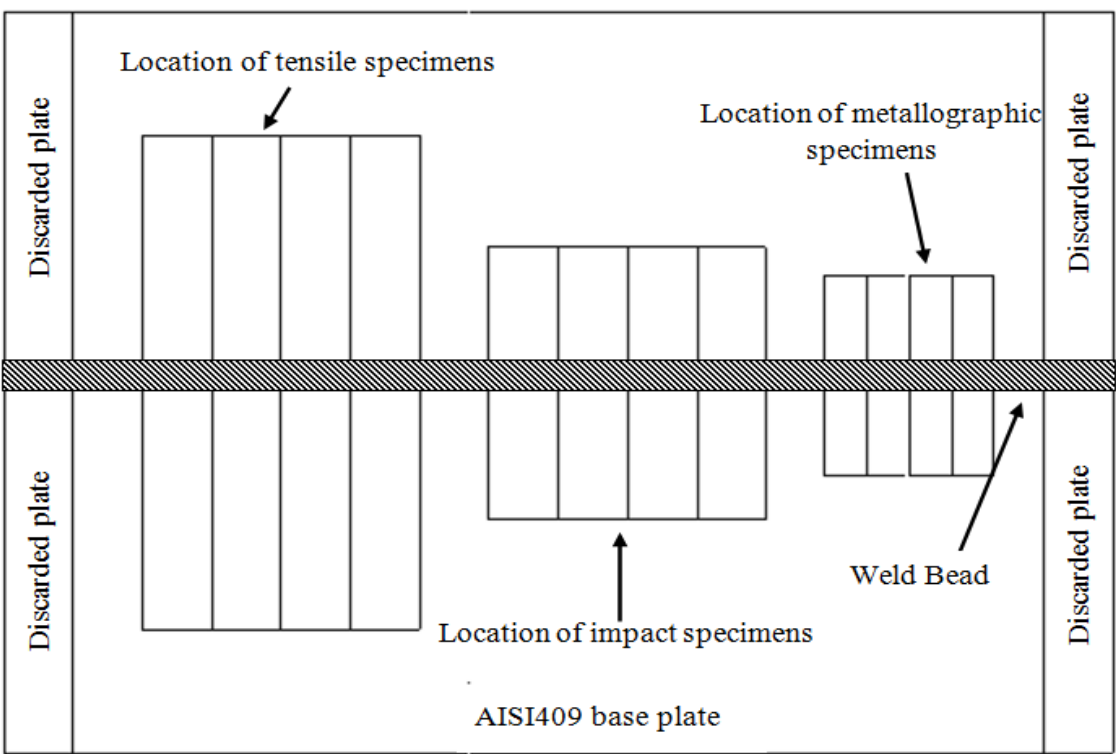

Fig. 2. Layout for specimen extraction from welded plate. 


\section{Specimens preparations}

Two sets of specimens for metallography analysis and mechanical testings were extracted from the welded plate using wire cut electron-discharge machining, as shown in Fig. 2. Metallographic specimens comprised of base metal (BM), heat affected zone (HAZ), and weld zone were extracted in the transverse direction to the weld joint. Similarly, two sets of specimens were extracted for tensile tests as per the ASTM E8 guidelines [37] and impact test as per ASTM E23-12C [38] guidelines in the direction perpendicular to the weld joint as shown in Fig. 3.

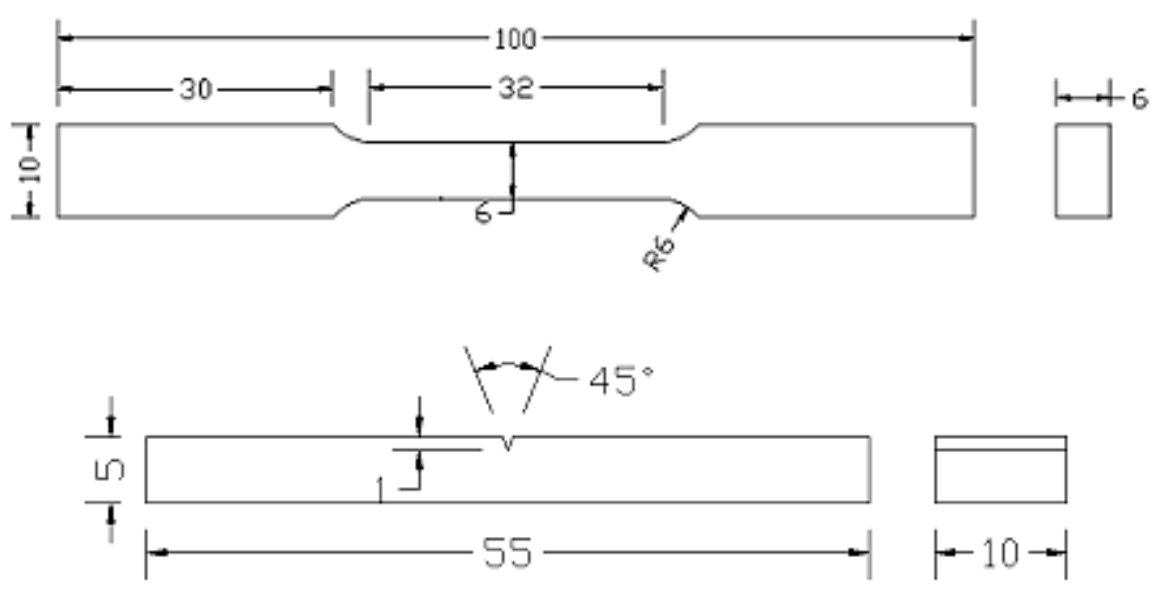

Fig. 3. Dimensional specifications of the tensile and impact specimen.

\section{Post weld heat treatment}

To enhance the metallurgical behavior and mechanical properties of the weld joints one set from each test specimens was subjected to PWHT at a temperature of 550 ${ }^{\circ} \mathrm{C}$ for 75 minutes. A literature survey was followed to estimate the time and temperature for heat treatment that could be advantageous and avoid the embrittlement phenomenon [3, 32, 36, 39, 40].

\section{Metallography and mechanical testing}

The metallographic examination was conducted using macrostructure analysis, microstructural analysis, microhardness measurements, and XRD analysis. Standard procedures under ASTM E3-11 [41] guidelines were followed for preparations of samples that involve grinding and polishing with emery paper up to 3000 grit size and finally polishing with diamond paste on a velvet cloth. In order to reveal the microstructure, the polished specimens were etched using Villela reagent $(\mathrm{HCl}(5 \mathrm{ml})$, picric acid $(1 \mathrm{~g})$, and ethanol $(100 \mathrm{ml}))$ [42]. Macrostructure and microstructure analysis was conducted with an optical microscope coupled with a CCD camera. Further, specimens were analyzed under XRD for the identification of various phases.

Microhardness measurements were carried using a load of $1 \mathrm{~kg}$ for 30 seconds on Vicker's testing machine. Measurements were recorded along the weld centerline (top to bottom) with a gap of $0.5 \mathrm{~mm}$ and across the weld centerline from left to right at a gap of $0.15 \mathrm{~mm}$ on the metallography specimens. 
Transverse tensile testing was performed on a servo-controlled hydraulic testing machine at room temperature with a load of $50 \mathrm{kN}$ and a strain rate of $4 \mathrm{~mm} / \mathrm{min}$. The tensile properties were evaluated by analyzing the ultimate tensile strength (UTS) and yield strength (YS). The impact toughness tests were performed at room temperature on a pendulum-type impact testing machine. Notch was machined at the weld centerline to identify the weld zone toughness. V-notch was precisely cut on all the specimens to avoid variations in the results.

\section{Results and Discussion}

\section{Morphology/Macrostructure Analysis}

Fig. 4 represents the macrostructural image of the weld joint fabricated using the EBW process. The optical micrograph contained base metal, heat affected zone (HAZ), and weld zone (WZ). Dagger shaped joint was obtained, wider at the top region $(6.78 \mathrm{~mm})$ and narrow at the bottom region $(2.44 \mathrm{~mm})$ that describe the keyhole techniques related to EBW. The weld cross-section expressed the joint as a distinctive shape with a large depth to width ratio of 5.14:1 and small HAZ. The image also confirmed the transverse section of the weld joint is intact and free from any defect like porosity, cracks. The weld was fully penetrated up to $18 \mathrm{~mm}$ thickness of the plate and $2 \mathrm{~mm}$ of the backing plate. The morphology of the weld joints confirms that AISI 409 FSS can be successfully welded using the EBW process in a single pass.

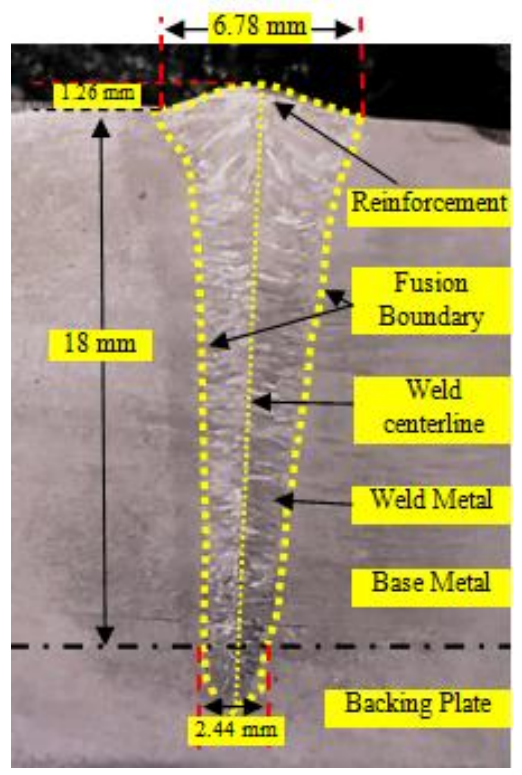

Fig. 4. Macroscopic image of welded joint. 


\section{Microstructural Analysis}

The optical microstructure of the regions, BM, WZ, and HAZ zone at 100x are shown in Fig. 5, Fig. 6, and Fig. 7. The microstructure of base metal is predominantly composed of equiaxed ferritic grains, as shown in Fig. 5(a), but the effect of PWHT at $550{ }^{\circ} \mathrm{C}$ for 75 minutes on the base metal was to increase the martensite at the grain boundaries, which is visible from Fig. 5(b). This increase in martensite would be the reason for the increase in microhardness of base metal after PWHT. Grain coarsening exists in WZ and HAZ due to thermal weld cycles. The grain size of the WZ was found to be enlarged in comparison with the base metal and HAZ. The enlargement of the grains depends upon the period it remains heated, and the intensity of heat experienced [43]. The WZ mainly consisted of enlarged columnar grains perpendicular to the weld centerline. The flow of heat during solidification of the weld zone is toward the sides of the fusion boundary; this would be due to the square butt shape and the temperature variations between the weld pool and BM that causes the grains to grow towards that direction in columnar shape (Fig. 6a). Taban et al. [11] and Lakshminarayanan et al. [44] mentioned a similar grain structure after welding with EBW and LBW process. The microstructure of HAZ revealed that finer grains with martensite island at the grain boundaries (Fig. 7a). The formation of martensite acts as a hindrance in the growth of grains and restricts the enlargement of grains to some extent. Further, the post-weld heat treatment at $550{ }^{\circ} \mathrm{C}$ for 75 minutes gave a significant improvement in the grain structure that subsequently improves the impact and tensile toughness. The enlarged columnar grains in the weld zone were transformed into smaller refined grains, as can be seen in Fig. 6(b) and 7(b). X-ray diffraction technique was employed to justify the ferrite structure and to reveal the presence of carbides in the specimens. Due to the low chromium content of base metal, the carbide formation was restricted in the weld zone, and the XRD peaks show only ferrite structure (Fig. 8).
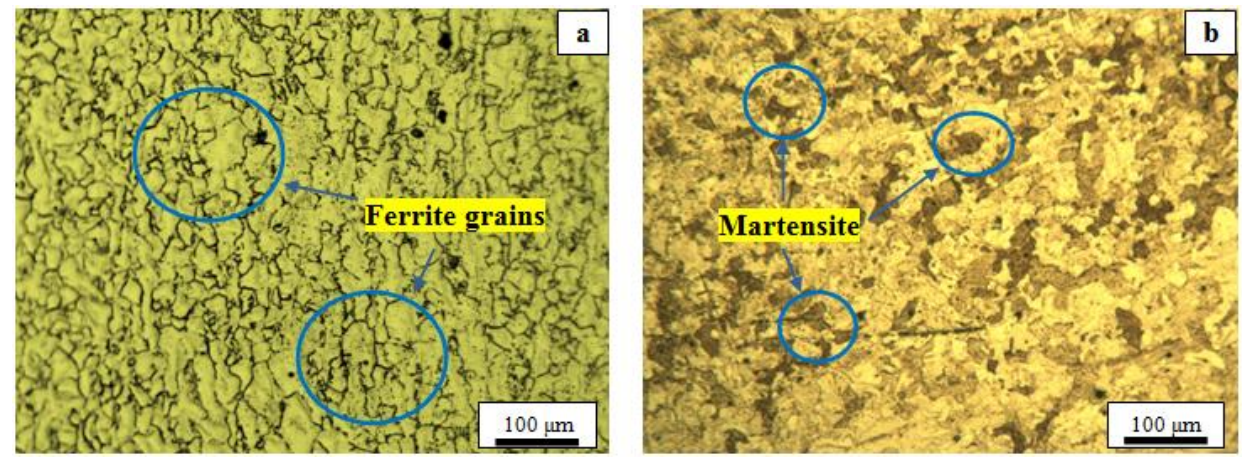

Fig. 5. The microstructure of the base metal AISI 409 (a) as-welded condition (b) after PWHT condition. 


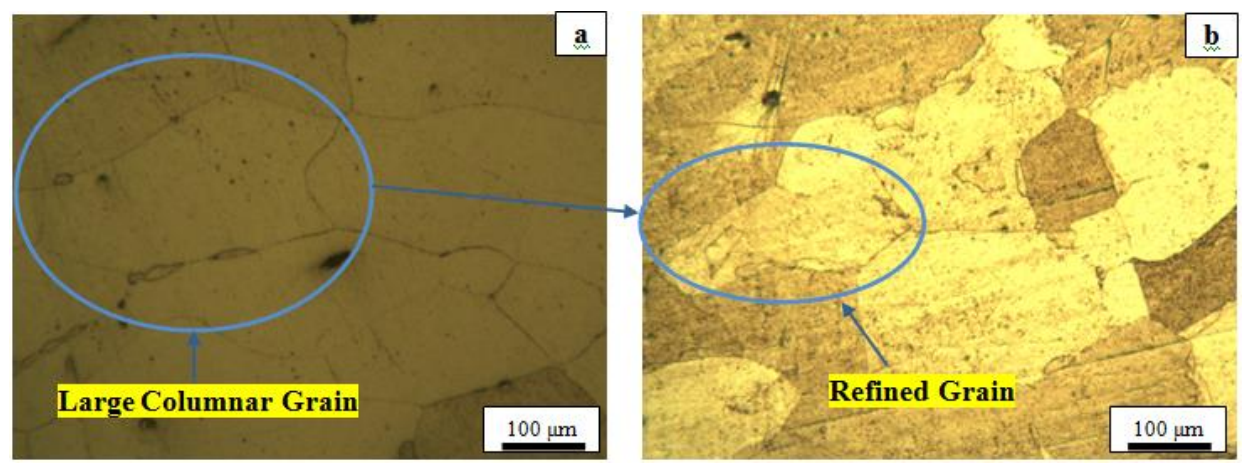

Fig. 6. The microstructure of the weld zone (a) as-welded condition (b) after PWHT condition.

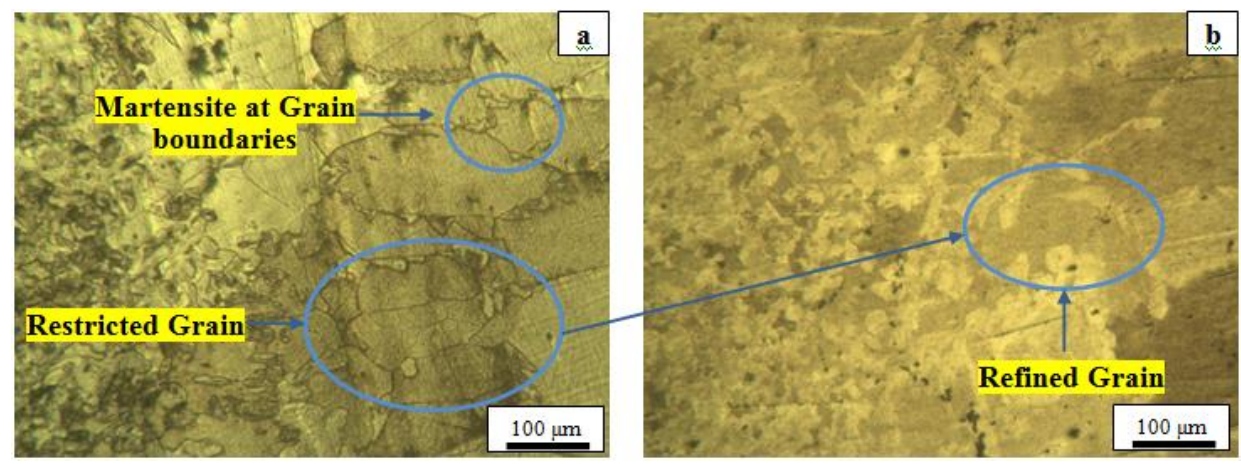

Fig. 7. The microstructure of the HAZ zone (a) as-welded condition (b) after PWHT condition.

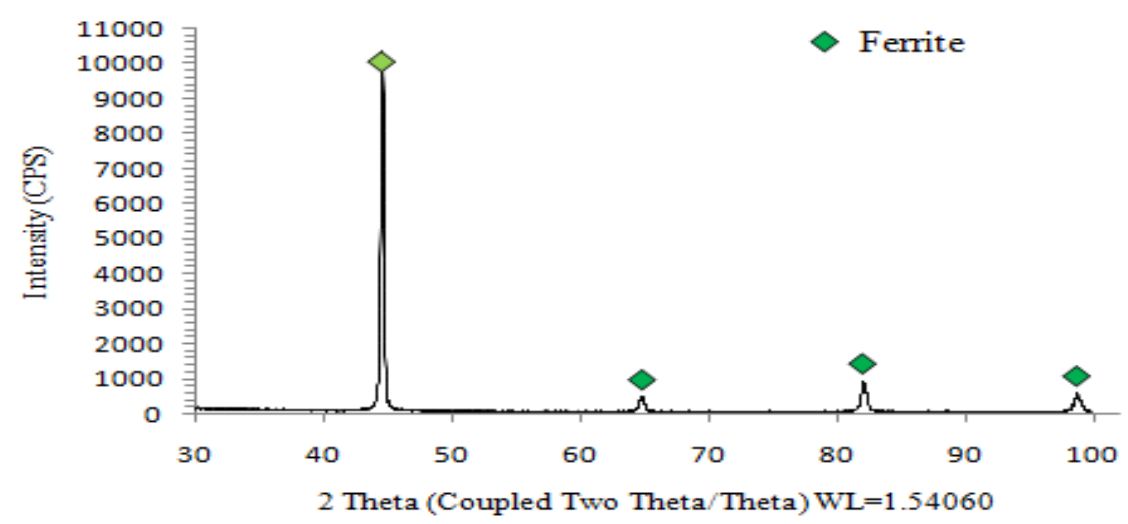

Fig. 8. X-ray diffraction profile of weld zone. 


\section{Microhardness}

The microhardness measurements were taken across the weld bead covering BM, $\mathrm{HAZ}$, and $\mathrm{WZ}$ at a gap of $0.5 \mathrm{~mm}$ and along with the weld bead from top to bottom at a gap of $0.15 \mathrm{~mm}$. Fig. 9 graphically illustrates the average value of microhardness for aswelded specimens and after PWHT specimens. The average microhardness value of HAZ and WZ in the as-welded condition was found to be higher than the BM. This may be attributed to the consequence of the grain coarsening phenomenon that arises due to the weld heat input. Further, the maximum microhardness was recorded in the HAZ region, which was $41 \%$ higher than the $\mathrm{BM}$ and $19 \%$ higher than the WZ. The high increase in microhardness might be due to the development of martensite at the grain boundaries of the HAZ region. The average microhardness of the weld zone was found varying between 184.4 - $199 \mathrm{HV} 1$. The post-weld heat treatment of the weld specimens gave encouraging results in terms of microhardness values. The average microhardness values of the WZ and HAZ were found to be reduced by $10 \%$. The fall in microhardness value would be due to the refinements of grains structure after PWHT. Further, the microhardness values of the BM were increased by $38 \%$ after the PWHT; this would be due to the formation of martensite in the BM structure. Martensite being a hard constituent increases the microhardness value, and also increases the brittleness.

Fig. 9(b) graphically illustrates the average microhardness values along the weld centerline. The increasing trend of microhardness was recorded while traversing from top to bottom. The maximum microhardness of $201.7 \mathrm{HV} 1$ was recorded at the bottom of the weld centerline, and minimum microhardness was recorded at the top of the weld centerline i.e. 177.4 HV1. This variation in microhardness values is attributed to the grain structure variation owing to the cooling rate difference due to the presence of a backing plate at the bottom. After PWHT, a reduction in microhardness was observed throughout the weld zone.

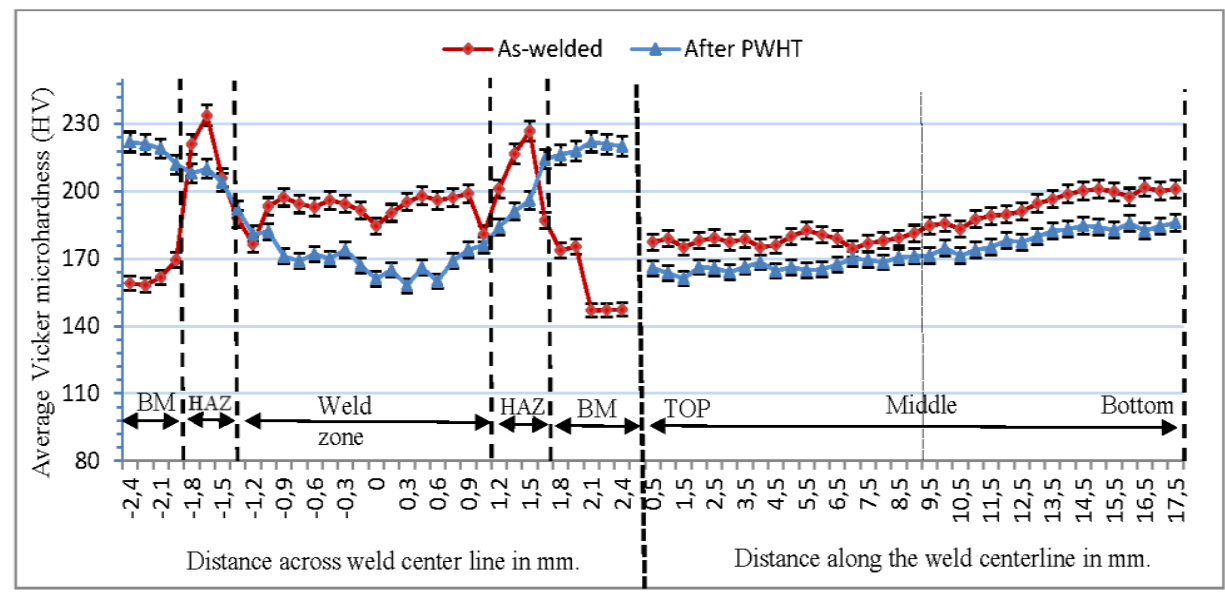

Fig. 9. The average value of microhardness

(a) across the weld bead and (b) along the weld centerline (error percentage 2\%). 


\section{Tensile properties}

Tensile tests were carried out to evaluate the YS and UTS of welded joints at room temperature in the as-welded condition and after PWHT condition. Fig. 10 displays the recorded value of the average UTS and YS. All the as-welded and PWHT specimens got fractured at the base metal; this showed that WZ and HAZ were found stronger than the BM. Grain coarsening in the weld zone has caused no adverse effect on the tensile properties. Vidyarthy et al. [35] and Deleu et al. [7] also reported similar trends when welded ferritic stainless steel. The tensile results of as-welded specimens were found in trends with the microhardness results.

After PWHT at $550{ }^{\circ} \mathrm{C}$ for 75 minutes, an increase in UTS and YS were observed. Although the microhardness of the WZ was lesser than the BM still, the fracture occurred at the BM. This might be due to the formation of martensite in the $\mathrm{BM}$, solidification structure attained in $\mathrm{WZ}$ due to fast cooling rate, and the columnar shaped grains that exist perpendicular to the crack propagation direction. An improvement of 5\% in UTS and 10\% in YS was recorded after PWHT.

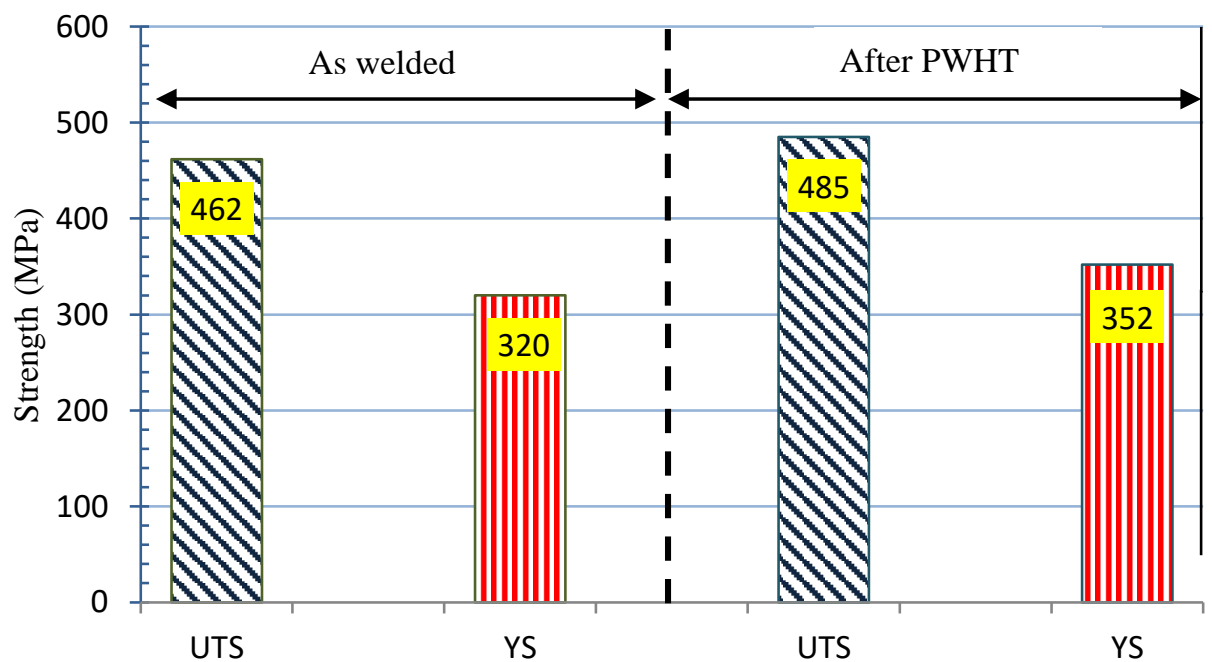

Fig. 10. Average ultimate tensile strength (UTS) and yield strength (YS) of as-welded and after PWHT specimens (error percentage 3\%).

\section{Impact test}

The impact toughness properties of weld joints were evaluated at room temperature using a Charpy testing machine with a notch at the WZ. The average of absorbed energy for WZ and BM of as-welded specimens and PWHT specimens is presented in Fig. 11. The absorbed energy of the WZ was found lower than the WZ. This decline in the toughness of WZ after EB welding is attributed to grain growth. The microstructure evolution after solidification of the weld pool directly affects the toughness values of the joint [9]. The average impact toughness of the as-welded WZ specimen was found to be $25 \mathrm{~J}$, which is $45 \%$ lower than BM; still, it is considered in the acceptable limits. The PWHT at $550{ }^{\circ} \mathrm{C}$ for 75 minutes resulted in a significant 
improvement of impact toughness. An improvement of $40 \%$ was recorded after PWHT that suggests the heat treatment to be effective for AISI 409 FSS.

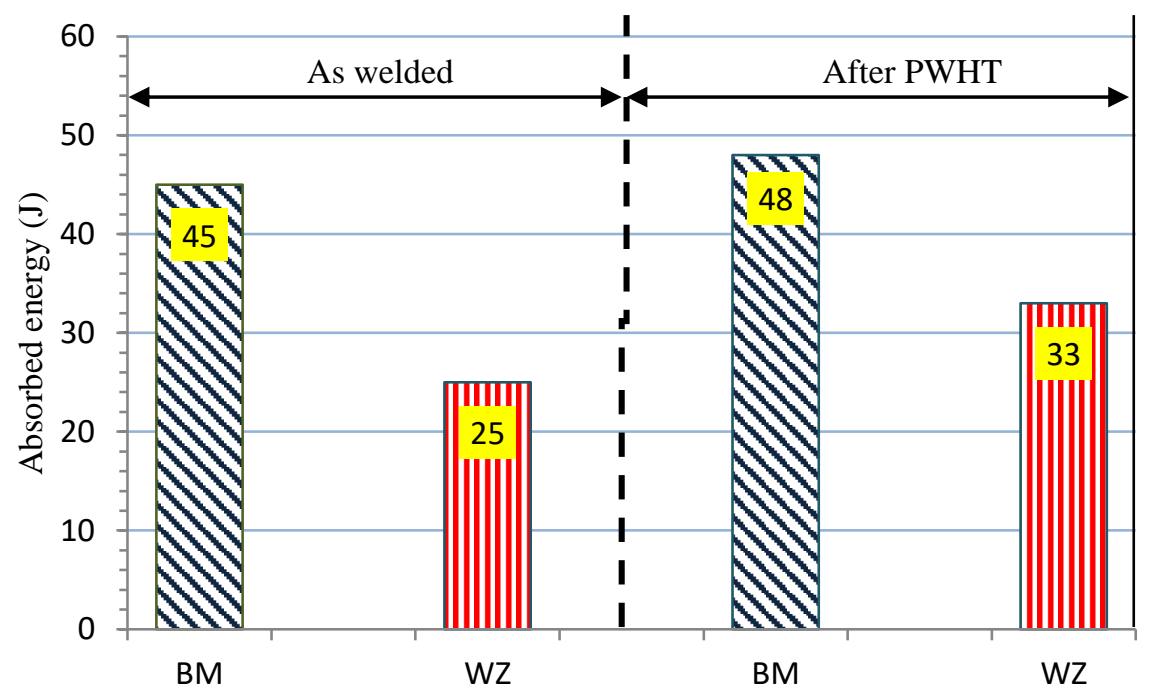

Fig. 11. The average value of impact toughness of weld zone and base metal specimens in as-welded condition and after PWHT condition (error percentage 5\%).

Fractography of impact and tensile specimens

The fractured ends of impact specimens were investigated with scanning electron microscopy. Fig. 12 shows the fractographs of fractured ends for as-welded and PWHT specimens after the impact test. Investigations of as-welded specimens revealed brittle cleavage, and large voids, along with few ductile dimples, were present. This indicates mostly the brittle behavior of the specimen. Further, PWHT at $550^{\circ} \mathrm{C}$ for 75 minutes transforms the mode towards ductile fracture as voids were reduced, and shear dimples were seen. The fracture behavior was found consistent with impact toughness, as an enhancement in toughness was seen after PWHT.

Fig. 13 shows the fractographs of fractured tensile tested specimens in as-welded and after PWHT condition. Fig. 13(a) indicates brittle cleavages with large voids and cracks. Whereas,PWHT specimens showed the combination of both brittle and ductile behavior with small voids and ductile dimples. This signifies the improvement in the tensile properties of specimens after PWHT. 

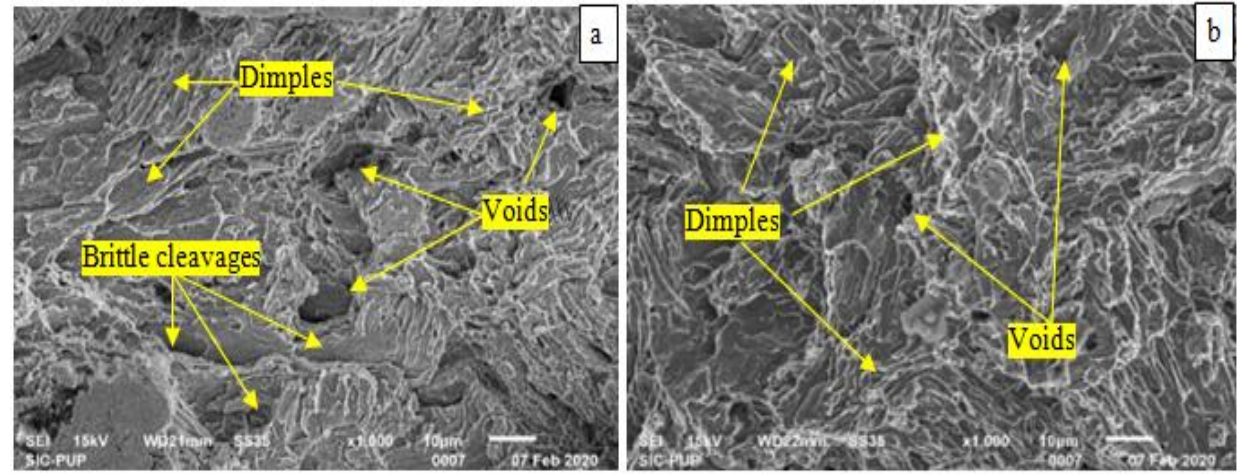

Fig. 12. SEM Fractographs of the impact specimens (a) as-welded (b) after PWHT.
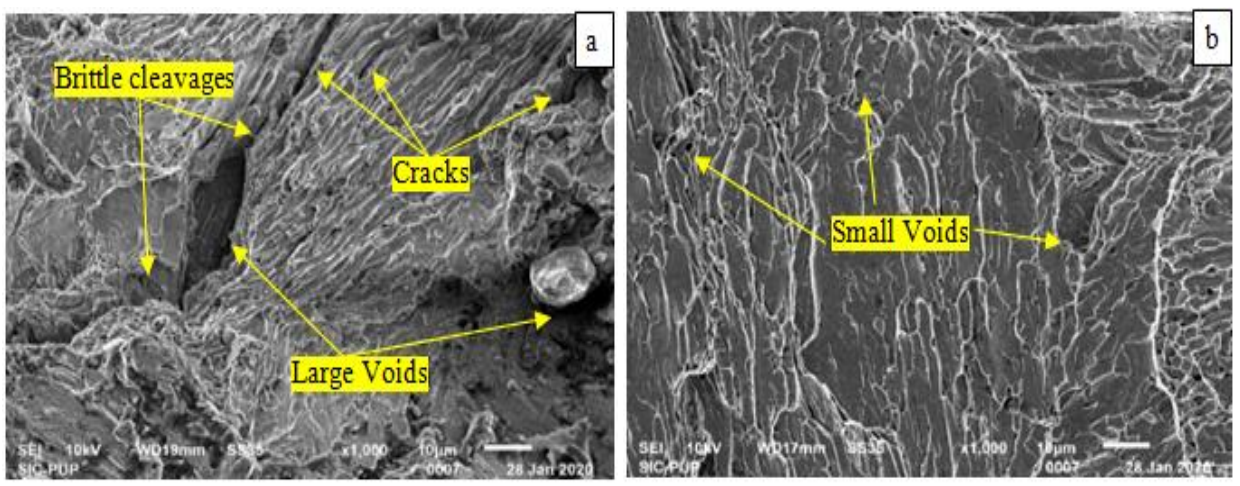

Fig. 13. SEM Fractographs of the tensile specimens (a) as-welded (b) after PWHT.

\section{Conclusions}

The following conclusions have been drawn related to the weldability of $18 \mathrm{~mm}$ thick AISI 409 ferritic stainless steel using EBW process:

- The defect-free weld joint of an $18 \mathrm{~mm}$ thick AISI 409 ferritic steel plate can be successfully obtained using an electron beam welding process.

- The microhardness of the WZ and HAZ was found $20 \%$ and $41 \%$ higher than the BM. This might be due to the grain coarsening effect. Further, the microhardness along the weld centerline was found to increase from top to bottom; this may be attributed to the cooling rate variation between the top and bottom.

- All the tensile specimens fractured from the BM. This indicates that the grain coarsening does not have any negative effect on the tensile properties.

- The impact toughness of the weld joint was found to be reduced by $45 \%$.

- The post-weld heat treatment at $550{ }^{\circ} \mathrm{C}$ for 75 minutes improved the microstructural and mechanical properties. The grains were found to be 
refined, and the tensile strength and impact toughness was improved by $10 \%$ and $40 \%$.

\section{Acknowledgments}

The authors acknowledge the Mechanical Engineering Department, IKG Punjab Technical University, Kapurthala, for providing the opportunity to do the research work and also acknowledge the Mechanical Engineering Department, Sant Longowal Institute of Engineering and Technology, Longowal, Punjab, for the facilities provided to carry out research work.

\section{References}

[1] D.J. Kotecki, T.A. Siewert, Weld. Res. Suppl. 71 (1992) 171-178.

[2] Robert G. Nooning, Effect of Stabilizing Elements on the Precipitation Behavior and Phase Stability of Type 409 Ferritic Stainless Steel, 2002.

[3] M.O.H. Amuda, E. Akinlabi, M. S., Ref. Modul. Mater. Sci. Mater. Eng. (2016) $1-18$.

[4] S. Anttila, P. Karjalainen, S. Lantto, Weld. World 57 (2013) 335-347.

[5] N.E. Dan, S.N.S. Mohd Sabri, P. Hussain, H. Mohebbi, in: J. Phys. Conf. Ser., IOP Publishing, 2018, pp. 1-6.

[6] T.C. Mamphekgo, V.J. Matjeke, K. Pillay, in: IOP Conf. Ser. Mater. Sci. Eng., IOP Publishing, 2018, pp. 1-8.

[7] E. Deleu, A. Dhooge, E. Taban, E. Kaluc, Weld. World 53 (2009) 198-208.

[8] M.O.H. Amuda, S. Mridha, Mater. Des. 47 (2013) 365-371.

[9] C.J. Van Niekerk, M. Du Toit, M.W. Erwee, Weld. World 56 (2012) 55-64.

[10] M. Du Toit, C.J. Van Niekerk, J. South. African Inst. Min. Metall. 111 (2011) 243-256.

[11] E. Taban, E. Deleu, A. Dhooge, E. Kaluc, Mater. Des. 30 (2009) 1193-1200.

[12] D.H. Kah, D.W. Dickinson, Weld. Res. Suppl. 60 (1981) 135-142.

[13] M.O.H. Amuda, S. Mridha, Adv. Mater. Res. 86 (2010) 1165-1172.

[14] T. Mohandas, G. Madhusudhan Reddy, M. Naveed, J. Mater. Process. Technol. 94 (1999) 133-140.

[15] A.K. Lakshminarayanan, K. Shanmugam, V. Balasubramanian, J. Iron Steel Res. Int. 16 (2009) 62-68.

[16] G. Ipekoglu, K. Kucukomeroglu, S.M. Aktarer, D.M. Sekban, G. Cam, Mater. Res. Express 6 (2019) 46537.

[17] T. Küçükömeroğlu, S.M. Aktarer, G. İpekoğlu, G. Çam, Int. J. Miner. Metall. Mater. 25 (2018) 1457-1464.

[18] G. Çam, G. Ipekoglu, T. Küçükömeroglu, S.M. Aktarer, J. Achiev. Mater. Manuf. Eng. 80 (2017) 65-85.

[19] T. Küçükömeroğlu, S.M. Aktarer, G. İpekoğlu, G. Cam, Mater. Test. 60 (2018) 1163-1170.

[20] G. Çam, M. Koçak, Sci. Technol. Weld. Join. 3 (1998) 105-126.

[21] G. Çam, Ç. Yeni, S. Erim, V. Ventzke, M. Koçak, Sci. Technol. Weld. Join. 3 (1998) 177-189.

[22] J.F. dos Santos, G. Cam, S. Riekehr, V. Ventzke, Weld. World 44 (2000) $42-$ 
64.

[23] G. Çam, M. Koçak, Int. Mater. Rev. 43 (1998) 1-44.

[24] G. Çam, Int. Mater. Rev. 56 (2011) 1-48.

[25] A. Kumar, S.S. Sandhu, B. Singh, in: Miner. Met. Mater. Ser., Springer International Publishing, 2020, pp. 169-180.

[26] C.I.M.C.E. Consultant, M. Bungalow, 6 (1985) 285-291.

[27] A.K. Lakshminarayanan, V. Balasubramanian, G.M. Reddy, Int. J. Adv. Manuf. Technol. 1 (2011) 153-162.

[28] M. Tullmin, F.P.A. Robinson, C.A.O. Henningt, A. Strausst, J. Le Grange, 89 (1989) 243-249.

[29] P. Havlík, P. Šohaj, J. Kouril, R. Foret, I. Dlouhý, Methods 4 (2014) 5-6.

[30] S.S. Sandhu, A.S. Shahi, J. Mater. Process. Technol. 233 (2016) 1-8.

[31] E. Taban, E. Kaluc, A. Dhooge, Mater. Des. 30 (2009) 4236-4242.

[32] M. Keskitalo, J. Sundqvist, K. Mäntyjärvi, J. Powell, A.F.H. Kaplan, Phys. Procedia 78 (2015) 222-229.

[33] M.S. Rajadurai, S. Naveen, M. Afnas, T. Arun, N. Kumar, S. Surendhar, Int. J. Recent Dev. Eng. Technol. 4 (2015) 23-36.

[34] A. Doomra, S.S. Sandhu, B. Singh, Int. J. Eng. 18 (2020) 23-28.

[35] R.S. Vidyarthy, D.K. Dwivedi, M. Vasudevan, J. Mater. Eng. Perform. 26 (2017) 1391-1403.

[36] V.L. Manugula, K. V. Rajulapati, G.M. Reddy, K.B.S. Rao, Mater. Sci. Eng. A 698 (2017) 36-45.

[37] ASTM Standard E8, ASTM Int. (2013) 1-27.

[38] ASTM standard E 23-12c, ASTM Int. (2013) 1-25.

[39] C. Kose, C. Topal, Mater. Res. Express 6 (2019) 1-20.

[40] J.C. Lippold, D.J. Kotecki, Welding Metallurgy and Weldability of Stainless Steel, A Wiley-Inderscience publication, 2006.

[41] ASTM standard E3-11, ASTM Int. 82 (2016) 1-15.

[42] ASTM Standard E407-99, ASTM Int. (2012) 1-21.

[43] S.K. Gupta, A.R. Raja, M. Vashista, M.Z.K. Yusufzai, Mater. Res. Express 6 (2018) 1-46.

[44] A.K. Lakshminarayanan, V. Balasubramanian, Mater. Manuf. Process. 26 (2011) 37-41.

\section{(c) (7) Creative Commons License}

This work is licensed under a Creative Commons Attribution 4.0 International License. 